\title{
An Improved Crop Scouting Technique Incorporating Unmanned Aerial Vehicle-Assisted Multispectral Crop Imaging into Conventional Scouting Practice for Gummy Stem Blight in Watermelon
}

\author{
Melanie Kalischuk, ${ }^{1, \dagger}$ Mathews L. Paret, ${ }^{1,2, \dagger}$ Joshua H. Freeman,,${ }^{1,3}$ Darren Raj, ${ }^{4}$ Susannah Da Silva, ${ }^{1}$ Shep Eubanks, ${ }^{5}$ D. J. Wiggins, ${ }^{5}$ \\ Matthew Lollar, ${ }^{6}$ James J. Marois, ${ }^{7}$ H. Charles Mellinger, ${ }^{7}$ and Jnaneshwar Das ${ }^{8}$ \\ ${ }^{1}$ North Florida Research and Education Center, University of Florida-Institute of Food and Agricultural Sciences (UF-IFAS), \\ Quincy, FL, 32351 \\ ${ }^{2}$ Plant Pathology Department, UF-IFAS, Gainesville, FL, 32611 \\ ${ }^{3}$ Horticultural Sciences Department, UF-IFAS, Gainesville, FL, 32611 \\ ${ }^{4}$ Agribugs Inc., Tallahassee, FL, 32303 \\ ${ }^{5}$ Gadsden County Extension, UF-IFAS Cooperative Extension Service, Quincy, FL, 32351 \\ ${ }^{6}$ Jackson County Extension, UF-IFAS Cooperative Extension Service, Marianna, FL, 32448 \\ ${ }^{7}$ Glades Crop Care Inc., Jupiter, FL 33458 \\ ${ }^{8}$ School of Earth and Space Exploration, Arizona State University, Tempe, AZ, 85287
}

Abstract

\begin{abstract}
Multispectral imaging is increasingly used in specialty crops, but its benefits in assessment of disease severity and improvements in conventional scouting practice are unknown. Multispectral imaging was conducted using an unmanned aerial vehicle (UAV), and data were analyzed for five flights from Florida and Georgia commercial watermelon fields in 2017. The fields were rated for disease incidence and severity by extension agents and plant pathologists at randomized locations (i.e., conventional scouting) followed by ratings at locations that were identified by differences in normalized difference vegetation index (NDVI) and stress index (i.e., UAV-assisted scouting). Diseases identified by the scouts included gummy stem blight, anthracnose, Fusarium wilt, Phytophthora fruit rot, Alternaria leaf spot, and cucurbit leaf crumple disease. Disease incidence and severity ratings were significantly different between conventional and UAV-assisted scouting $(P<0.01$, Bhapkar/exact test). Higher severity
\end{abstract}

ratings of 4 and 5 on a scale of 1 to 5 from no disease to complete loss of the canopy were more consistent after the scouts used the multispectral images in determining sampling locations. The UAV-assisted scouting locations had significantly lower green, red, and red edge NDVI values and higher stress index values than the conventional scouting areas $(P<0.05$, ANOVA/Tukey), and this corresponded to areas with higher disease severity. Conventional scouting involving human evaluation remains necessary for disease validation. Multispectral imagery improved watermelon field scouting owing to increased ability to identify disease foci and areas of concern more rapidly than conventional scouting practices with early detection of diseases $20 \%$ more often using UAV-assisted scouting.

Keywords: drone-assisted scouting, UAV, precision agriculture, watermelon, cucurbits
Watermelon is an important summertime fruit that is full of healthpromoting components including lycopene, $\beta$-carotene, vitamin $\mathrm{A}$, vitamin $\mathrm{C}$, vitamin B6, calcium, magnesium, potassium, and thiamin (Johnson et al. 2013). It is grown widely in 44 states in the United States, and Florida is a leading producer with a \$200 million farm gate value (http://www.nass.usda.gov). Many fungal diseases including anthracnose (Colletotrichum lagenarium), Cercospora leaf spot (Cercospora citrullina), gummy stem blight (Stagonosporopsis cucurbitacearum), Fusarium wilt (Fusarium oxysporum f. sp.

${ }^{\dagger}$ Corresponding authors: M. Kalischuk; mkalischuk@ufl.edu and M. L. Paret; paret@ufl.edu

The contents do not necessarily reflect the views or policies of the USDA nor does mention of trade names, commercial productions, services or organizations imply endorsement by the U.S. government.

Funding: This research was funded in whole through a sub-recipient grant (024058) awarded by the USDA through the Florida Department of Agriculture and Consumer Services (USDA-AMS-SCBGP-2016).

*The $\boldsymbol{e}$-Xtra logo stands for "electronic extra" and indicates that five supplementary figures and one supplementary table are published online.

The author(s) declare no conflict of interest.

Accepted for publication 3 February 2019.

(C) 2019 The American Phytopathological Society niveum), and powdery mildew (Podosphaera xanthii) (Keinath 2000; Keinath and Duthie 1998; Rennberger and Keinath 2018; Zhou and Everts 2004); oomycete diseases including downy mildew (Pseudoperonospora cubensis) and Phytophthora fruit rot (Phytophthora capsici) (Holmes et al. 2015; Rennberger and Keinath 2018; Kousik et al. 2012); bacterial diseases including angular leaf spot (Pseudomonas syringae pv. lachrymans) and bacterial fruit blotch (Acidovorax citrulli) (Newberry et al. 2017; Walcott 2005); and viral diseases including cucurbit leaf crumple disease, cucurbit yellow stunting disorder, and squash vein yellowing (Adkins et al. 2011; Polston et al. 2008) are severe threats to watermelon production in the United States.

Early detection of plant diseases is critical in establishing an effective management program and to avoid the spread of disease and subsequent yield loss (Lowe et al. 2017). Visual assessment by ground scouting is the most commonly used method to determine disease incidence and severity (Basu and Lin 1977; Lin et al. 1979). In the case of watermelon, field scouts (extension agents, commercial agricultural consultants, or other agricultural professionals) typically select two or three random locations within a field during each of their field visits. Based on the assessments for disease incidence and severity, management recommendations are provided to producers. This approach for detection of diseases is time consuming and only covers a small portion of a field, and the assessment results may be affected by scout rating repeatability and reliability (Bock et al. 2010; Nutter et al. 1993). The costs associated with the visual assessment limit field coverage, potentially biasing assessment and recommendations/no recommendations that lend to underestimation of disease incidence and severity. Overall, a successful plant disease survey should be accurate in 
pathogen identification, and severity should be rated consistently over time.

Whole-field multispectral imaging has the potential to be used as an alternative to the traditional field assessments for detecting disease in crops (Mazzetto et al. 2010; Samseemoung et al. 2017; VergaraDiaz et al. 2015). This approach incorporates high-resolution imaging and spectral reflectance of plants in the visible (400 to $700 \mathrm{~nm}$ ) and near-infrared (NIR; 700 to $1,000 \mathrm{~nm}$ ) ranges to provide health indicators at the field scale (Candiago et al. 2015). Normalized difference vegetation index (NDVI) is calculated and based on the property that reflectance is high in the NIR range and low in the visible wavebands. Plant canopy leaf area index and the amount of photosynthetically active radiation absorbed by the canopy are related to NDVIs, and this has led to the ability to successfully map fields based on biomass, yield, nutrient status, and moisture-related issues (Ballester et al. 2017; Marino and Alvino 2014; Vergara-Diaz et al. 2015). Plant disease significantly alters canopy architecture and host physiological processes, with changes and shifts in the production of primary and secondary metabolites (Costes et al. 2013; Kalischuk et al. 2015; Tivoli et al. 2013). Pathogen defense mechanisms associated with changes in metabolism and the synthesis of plant pigments chlorophyll, anthocyanins, and carotenoids (Demmig-Adams et al. 2013; Lo and Nicholson 1998) can also have an enormous impact on vegetation canopy reflectance patterns. Plant disease, symptom development, and the infection process is often host and pathogen specific (Barbosa et al. 2017; Keinath 2014); therefore, growth habit also may be an important component for spatial attributes of imaging. In recent years, spectral reflectance imaging has been used successfully in differentiating between healthy and stressed cucurbits affected with Cucumber mosaic virus, powdery mildew, or Cucumber green mottle mosaic virus (Berdugo et al. 2014; Kouakou et al. 2016). The largescale commercial availability of unmanned aerial vehicles (UAVs) provides the opportunity to attach multispectral sensors that can be used to identify areas of plant stress within a field in an inexpensive and relatively simple manner, if automated (Zhang and Kovacs 2012). UAVs can be used to survey an entire field quickly, easily, and with reduced human-associated damage to plants and soils (Ballester et al. 2017; Candiago et al. 2015; Link et al. 2013). A recent field study on watermelon showed that the use of UAV-NIR imagery indicated a strong negative correlation between gummy stem blight disease severity and NDVI values (Paret et al., unpublished data). However, studies on the use of NIR imagery or multispectral imagery on watermelon and its documented potential use in improving conventional scouting practices in watermelon are not available currently.

The objectives of this study were (i) to assess if a multispectral sensor mounted onto a UAV can be used to identify disease foci in commercial watermelon fields using green, red, and red edge NDVI and stress index information, (ii) to evaluate if UAV-assisted scouting can improve accurate assessment of disease incidence and disease severity in commercial watermelon fields compared with conventional scouting, and (iii) to study entire field temporal shifts in green, red, and red edge NDVI and stress index. The goal of this research is to establish improvements to current conventional scouting practices in watermelon through the use of UAV-assisted scouting. Currently, the conventional scouting procedure does not use imaging in the assessment. Increased consistency in detecting disease incidence and disease severity has the potential to lead to timely and appropriate management practices, therefore limiting disease spread resulting in increased yield and fruit quality.

\section{Materials and Methods}

Study sites. The studies were conducted in the summer and fall of 2017 in three commercial watermelon fields consisting of two located in Florida and one in Georgia. Two fields (1 and 3; Table 1) were drip irrigated, planted with transplants on raised beds with black plastic, and were 95 and 46 acres, respectively. Field 2 (Table 1) was 68 acres, overhead irrigated, and planted with transplants on raised beds with black plastic. The fields were prepared and maintained as per watermelon production guidelines for Florida and the southeastern United States (Freeman et al. 2016; Kemble et al. 2016). For fields 1 and 2, the watermelon variety in production was Melody (Syngenta, Greensboro, NC), and for field 3, the variety information was not available from the producer.

Acquisition of multispectral sensor data. All flights were completed within $2 \mathrm{~h}$ of solar noon on clear sunny days or light overcast days in which the ambient light was not changing. Flights of field 1 were completed on May 27 and June 9, 2017 (Table 1). Flights of field 2 were completed on June 17 and June 24, 2017. The flight of field 3 was completed on July 1, 2017. These dates corresponded to complete canopy closure and within 3 weeks before first fruit harvest. Weather data for the flight dates is provided in Supplementary Table S1. The flight pattern was perpendicular to the row direction so that stitching software (SlantRange, San Diego, CA) would be able to stich efficiently and accurately. The UAV platform consisted of a Matrice 100 quadcopter (Dà-Jiāng Innovations Science and Technology Co., Shenzhen, China) fitted with a DJI Z3 digital camera (Dà-Jiāng Innovations Science and Technology Co.), global positioning system (GPS), and multispectral sun iridescent 3p sensor (SlantRange). The sensor uses an iridescent sensor calibration algorithm that calibrates for solar angle automatically before launch. With this system, marker placement of known reflectivity is not required because a calibration adjustment is applied to each photo. The speed of the flights was $12 \mathrm{~m} / \mathrm{s}$ as determined by height set at $90 \mathrm{~m}$, and $75 \%$ front lap and overlap. The speed allowed one image to be captured every $2 \mathrm{~s}$, and imageprocessing procedures were automated using SlantView software guidelines (SlantRange). Automated procedures included piloting, image mosaicking, platform stability for roll, pitch, and yaw, geometric correction, ortho-rectification, and classification.

The sensor measured wavelengths of green $(550 \mathrm{~nm})$, red $(650 \mathrm{~nm})$, red edge $(709 \mathrm{~nm})$, and near-infrared $(820 \mathrm{~nm})$. Reflections of light at these wavelengths are sensitive for vegetation chlorophyll content and, therefore, may be reliable indicators of crop disease (Gitelson et al. 1996; Schuster et al. 2012). The reflectance patterns at these bandwidths have has been correlated with concentration of leaf chlorophyll, biomass, nutrient uptake, and yield (Gitelson et al. 1996; Moges et al. 2005). NDVIs were calculated according to those described in Candiago et al. (2015). A filter with a numerical value of 0.5 was applied to the photos during NDVI interpretation. This value was adequate to filter out the spectral response influenced by the characteristics of bare soil. Stress index is a proprietary algorithm incorporating four bandwidths and is indicated by the manufacturer as more sensitive than other indices to stress conditions. All flights were completed at an altitude of 91 to $94 \mathrm{~m}$ above ground level owing to size of acreage and resolution of $4 \mathrm{~cm}$ achieved. Based on acreage of field, the flights were

Table 1. Flight information for the field trials in commercial watermelon production

\begin{tabular}{|c|c|c|c|c|c|c|}
\hline Field & Location & Flight date & $\begin{array}{c}\text { Flight altitude } \\
\text { above ground (m) }\end{array}$ & Field size (acres) & Flight time (min) & Scout \\
\hline 1 & Florida & May 27, 2017 & 94 & 95 & 21.41 & Plant pathologist \\
\hline 1 & Florida & June 9, 2017 & 94 & 95 & 21.41 & Plant pathologist \\
\hline 2 & Georgia & June 17, 2017 & 92 & 68 & 19.09 & $\begin{array}{l}\text { Plant pathologist, } \\
\text { Extension agent }\end{array}$ \\
\hline 2 & Georgia & June 24, 2017 & 92 & 68 & 19.09 & $\begin{array}{l}\text { Plant pathologist, } \\
\text { Extension agent }\end{array}$ \\
\hline 3 & Florida & July 1,2017 & 92 & 48 & 11.44 & Extension agent \\
\hline
\end{tabular}


done at the aforementioned altitude to achieve proper front lap/overlap and reduce the number of battery changes during flight. The sensor is shut down during battery change and a new data set is created, which can have slightly different image calibration based on the time it takes to swap the battery and relaunch. To reduce this, achieving a flight with fewer battery changes is recommended. The flight can be flown lower, but it will take longer for data acquisition, which causes a multispectral and visual data set to have different solar angles, causing different shadowing, which can have an impact on NDVIs.

Scouting procedure. Scouts consisted of horticulture extension agents with at least 2 years of work experience and some experience in identification of diseases in the field and plant pathologists with specialized education and experience in identification of pathogens in the field and laboratory. Within 5 days following a flight, fields were scouted using conventional and UAV-assisted imagery procedures. Conventional scouting was completed at each site by walking randomly into the field and selecting two or more locations. Disease incidence and severity were observed along a predetermined path of 50-ft segment of two parallel rows (Basu and Lin 1977; Lin et al. 1979). Latitude and longitude coordinates were taken at the start and finish of each transect. Disease severity was rated individually for each disease using an ordinal scale used by commercial scouting companies. The scale was 1 for some plants showing symptoms, 2 for many plants showing symptoms and recommendation of pesticide treatment, 3 for many plants showing symptoms and rapidly spreading, 4 if disease is causing severe damage to the canopy and 50\% complete damage of the canopy, and 5 if the disease has caused $100 \%$ damage of the canopy.

Immediately after conventional scouting was completed, two or more locations based on UAV imagery were provided to the scouts to repeat disease incidence and severity ratings. Locations were based on the identification of potential disease foci as indicated by low NDVI and high stress index (stress index $>0.2$ ) values calculated using SlantView software. The maximum amount of time allowed for each disease assessment at an individual location within a field was $10 \mathrm{~min}$. All scouting pathogen identification and severity ratings were verified by experienced plant pathologists and diagnosticians using standard microscopy, microbiology, and molecular biology procedures.

Data analysis. The Bhapkar test for marginal homogeneity (Uebersax 2006) was applied to examine differences in the frequency distribution of severity ratings between conventional and UAVassisted scouting for all scouts. This is a nonparametric test that is more powerful than some other tests for assessing marginal homogeneity of matched-pair data but also tends to be fairly liberal. In these analyses, ratings were cross-paired between conventional and UAVassisted scouting. Stress index and green, red, and red edge NDVIs were calculated to make comparisons between the areas that were scouted using conventional and UAV-assisted methods for five flight dates. To do this, the mean NDVI or stress index values of five random pixels located near the GPS coordinates of the scouted region were compared using a two-way ANOVA with Tukey multiple comparison analysis using $\alpha=0.05$. Flight date and type of scouting were used as factors. Stress index and green, red, and red edge NDVI were not calculated for field 3 because this field had patchy plant growth owing to a transplanting issue.

\section{Results}

Diseases identified by the field scouts in the watermelon fields were high incidence of gummy stem blight and lower incidences of anthracnose, Fusarium wilt, Phytophthora fruit rot, Alternaria leaf spot, and cucurbit leaf crumple disease (Table 2). All stress reported was biotic except for abiotic symptoms in the form of sand blasting and mechanical damage that was reported $5 \%$ of the time by the extension agent scouts during the assessments. Misidentification of pathogens was less

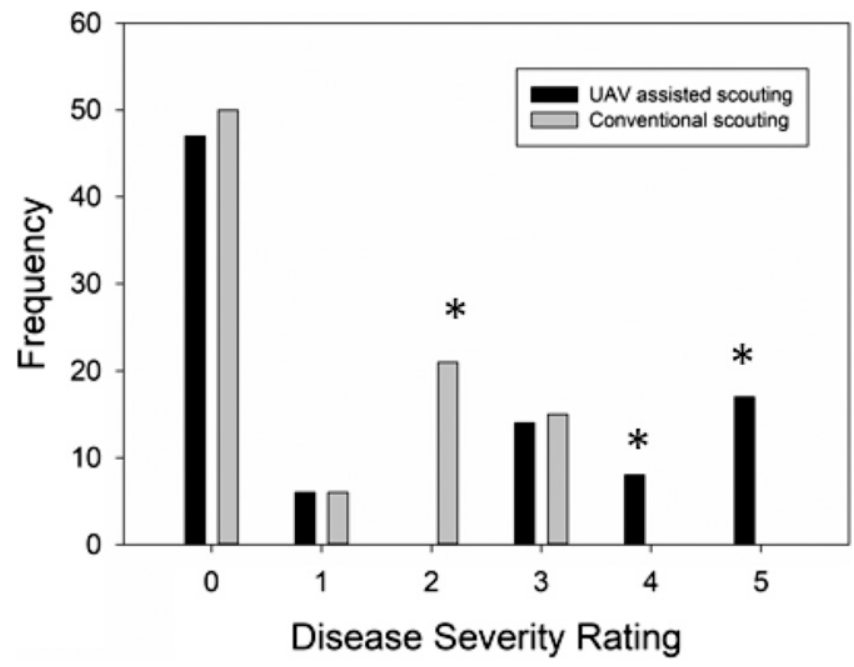

Fig. 1. Frequency distribution of disease severity ratings for conventional scouting and unmanned aerial vehicle (UAV)-assisted scouting completed by extension agents. Asterisk indicates significant differences using Bhapkar and Bonferroni-adjusted significance criteria with $P=0.05$ ( $n=92$ for each type of scouting).

Table 2. Incidence of diseases on watermelon indicating the percent of times the pathogen was present in the field scouted areas

\begin{tabular}{|c|c|c|c|c|c|c|c|c|}
\hline \multirow[b]{2}{*}{ Scout, date } & \multirow[b]{2}{*}{ Type of scouting ${ }^{a}$} & \multirow{2}{*}{$\begin{array}{c}\text { Number of scouted } \\
\text { locations }\end{array}$} & \multicolumn{6}{|c|}{ Disease incidence $(\%)^{\mathbf{b}}$} \\
\hline & & & GSB & PFR & ANTH & FUS & ALT & CuLCrD \\
\hline \multicolumn{9}{|c|}{ Plant pathologist } \\
\hline May 27 & Conventional & 2 & & & & & & \\
\hline May 27 & UAV & 2 & 50 & 50 & & & & \\
\hline June 9 & Conventional & 8 & 75 & 13 & 13 & & & \\
\hline June 9 & UAV & 8 & 100 & 38 & 50 & & & \\
\hline June 17 & Conventional & 3 & 66 & & & & & \\
\hline June 17 & UAV & 2 & 100 & & 100 & & & \\
\hline June 24 & Conventional & 3 & 100 & & & & & \\
\hline June 24 & UAV & 4 & 75 & 50 & 25 & 25 & & 25 \\
\hline \multicolumn{9}{|c|}{ Extension agent } \\
\hline June 17 & Conventional & 2 & 100 & & 50 & & & \\
\hline June 17 & UAV & 2 & 100 & & & & & \\
\hline June 24 & Conventional & 3 & 100 & & & & & \\
\hline June 24 & UAV & 3 & 67 & 33 & & 33 & & 33 \\
\hline July 1 & Conventional & 6 & 100 & & & & 17 & \\
\hline July 1 & UAV & 6 & 83 & & 17 & 17 & & 17 \\
\hline
\end{tabular}


than $3 \%$ of the time for extension agents, with anthracnose most commonly being mistaken for as gummy stem blight. The one occurrence of Fusarium wilt was not successfully cultured, and the symptoms may have been the result of an abiotic stress. The plant pathologist scouts identified pathogens at $100 \%$ accuracy. Scouting locations are provided in Supplementary Figures S1, S2, S3, S4, and S5.

UAV imagery improved conventional scouting. UAV-assisted scouting improved the accuracy of watermelon disease field scouting owing to the increased ability to identify disease foci and areas of concern more rapidly than the conventional scouting practice $(P<0.001$, Bhapkar test). Extension agent scouting data and analysis were based on two sites, three flight dates, four sets of individual scoutings, five categories of disease, and 92 disease ratings (Fig. 1). The disease

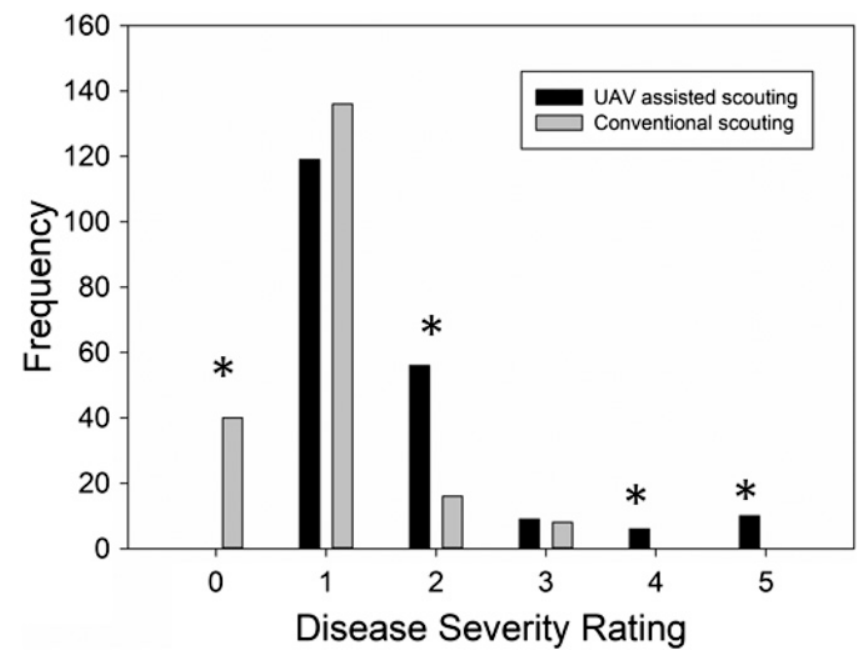

Fig. 2. Frequency distribution of disease severity ratings for conventional scouting and unmanned aerial vehicle (UAV)-assisted scouting completed by plant pathologists. Asterisk indicates significant differences using Bhapkar and Bonferroni-adjusted significance criteria of $P=0.05$ ( $n=200$ for each type of scouting).

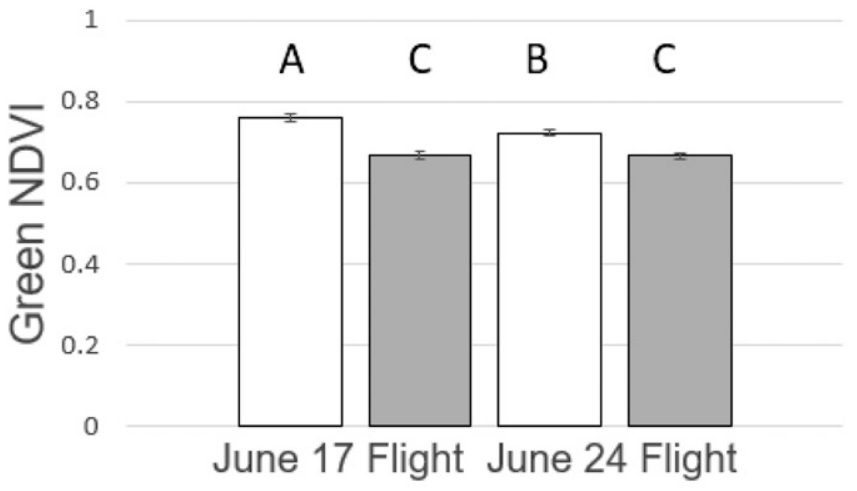

0.8

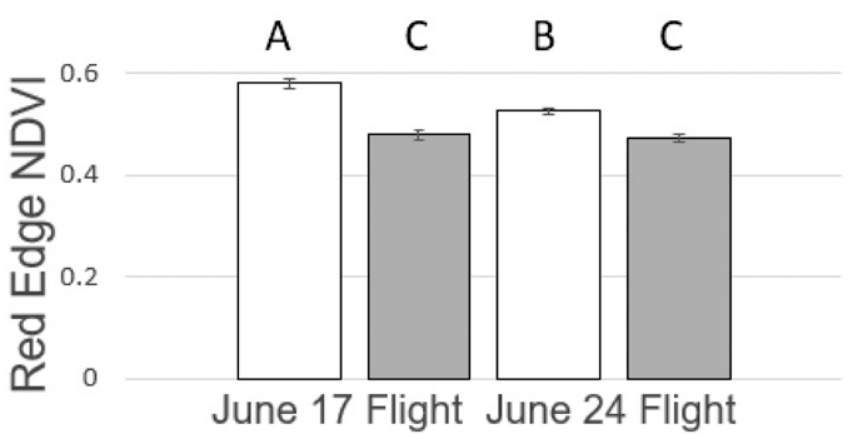

ratings of 4 and 5 were reported significantly more often during the UAV-assisted scouting than during the conventional scouting observations $(P<0.01$, Bonferroni adjustments). Lower severity ratings of 2 were reported significantly more often in the conventional scouting than with UAV-assisted scouting $(P<0.001$, Bonferroni adjustment). There were no statistical differences between both scouting approaches for disease severity ratings of 0 and 3 .

The plant pathologist scouting data and analysis was based on three sites, four flight dates, four sets of individual scoutings, five disease categories, and 200 disease ratings (Fig. 2). The scouting showed greater severity ratings during the UAV-assisted scouting than the conventional scouting $(P<0.001$, Bhapkar test). Disease severity rating 0 was significantly more frequent during the conventional scouting than the UAV-assisted scouting $(P<0.001$, Bonferroni adjustment). Severity ratings 2,4 , and 5 were significantly more frequent during the UAV-scouting than the conventional scouting $(P<0.001$, Bonferroni adjustment). There were no statistical differences between both scouting approaches for disease severity ratings of 1 and 3. The UAV-assisted scouting identified a disease 200 times, whereas the conventional scouting identified a disease 160 times, which is $20 \%$ less frequent for the conventional scouting at the same sampling intensity, and this was significant $(P<0.01$, Bonferroni adjustment).

Comparisons of NDVIs in conventional and UAV-assisted scouted areas. Stress index and NDVIs captured the temporal and spatial field dynamics and measured canopy health independent of the field scouting observations across three time periods (Figs. 3 and 4). With extension agents and plant pathologists the locations of conventional scouting had significantly greater green, red, and red edge NDVIs than the UAV-assisted scouted areas (Table 3, Figs. 3 and 4). Green and red edge NDVIs for conventional scouted areas significantly decreased as flights progressed in time. Significant differences were not detected for any of the mean NDVIs for the UAV-assisted scouting areas across flight dates.

The stress index showed an inverse relationship to NDVIs (Figs. 3 and 4). For each flight, UAV-assisted scouting locations had significantly greater stress index than the conventional scouting locations. Stress index increased with time at the areas scouted using

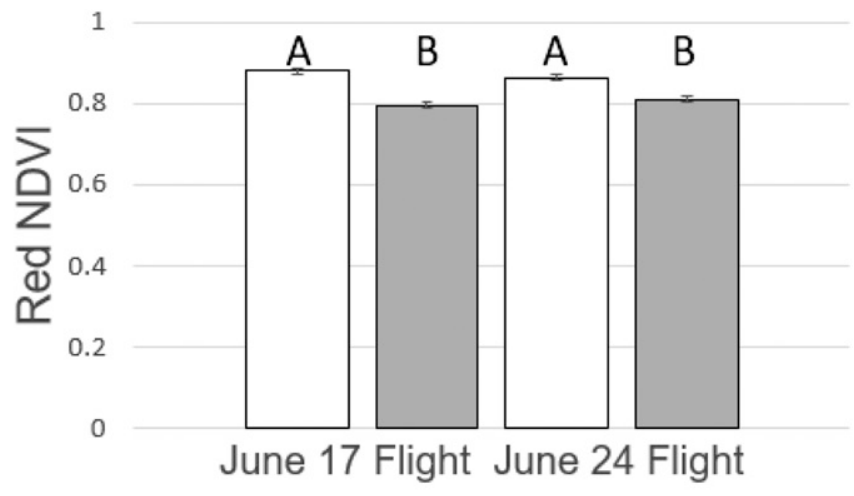

0.4

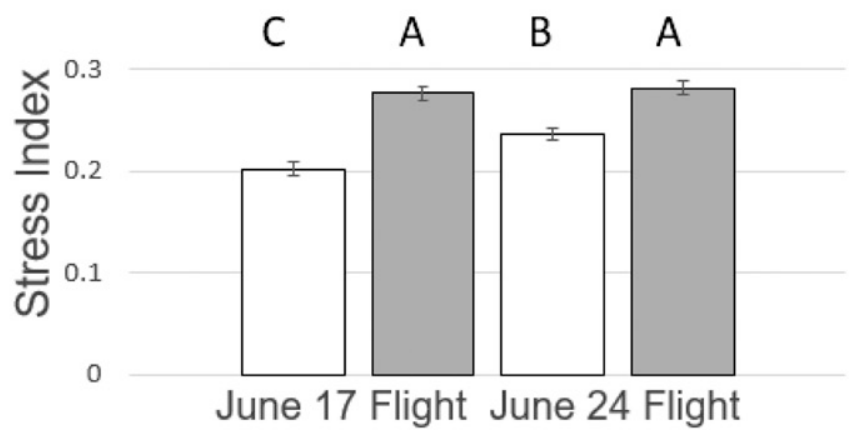

Fig. 3. Green normalized difference vegetation index (NDVI), red NDVI, red edge NDVI, and stress index values for conventional (white) and unmanned aerial vehicle-assisted (gray) scouting across two flight dates (June 17 and 24,2017 ) scouted by extension agents. Different letters above the bar indicate significant difference at $\alpha$ equal to $0.05(n=5)$. 
conventional methods. Stress index remained constant over time at locations scouted using UAV-assisted methods.

Entire field distribution of NDVIs. The trends in shifts in percentage distribution of the entire field NDVI values and stress index at incremental scales of $0.1 / 0.05$ for fields 1 and 2 are shown in Figures 5 and 6 . This shows key trends in changes in performance of watermelon crop development at the entire field level for individual scale range of NDVIs and stress index for both fields 1 and 2. In the case of green, red, and red edge NDVI, the highest percentage distribution of the field was found at value ranges of 0.7 to $0.8,0.8$ to 0.9 , and 0.5 to 0.6 for both fields at all flight dates. In the case of stress index, the highest percentage distribution of the field was at the value range of 0.15 to 0.20 for both fields and all flight dates, except for June 9, for which 0.20 to 0.25 was the range with the highest percentage distribution of the field. For field 1, from May 27 to June 9 , the green, red, and red edge for the above peak NDVI scales, the
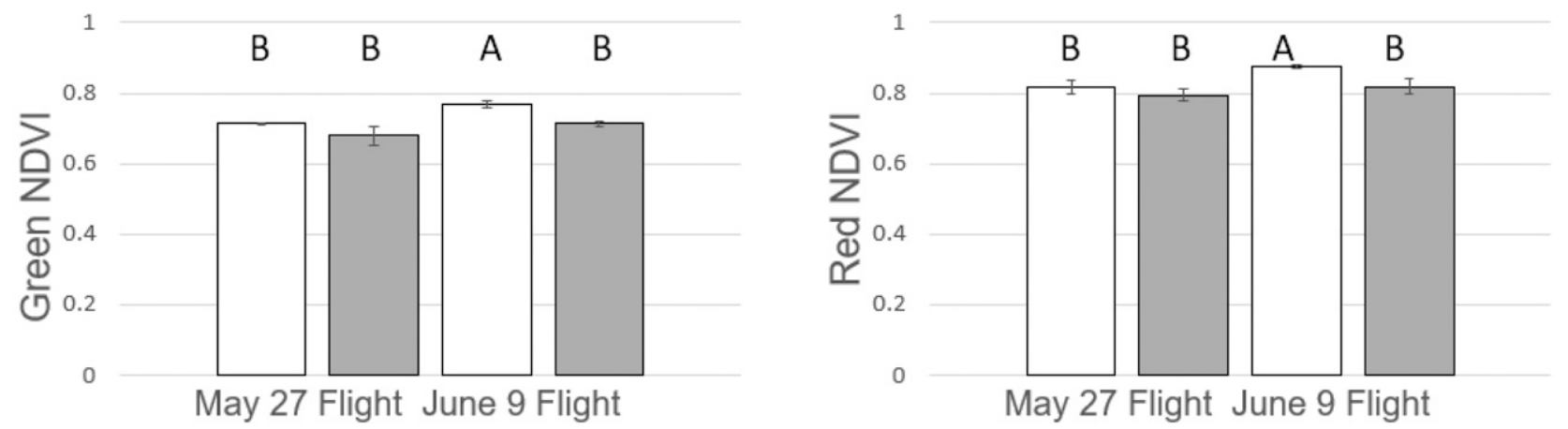

0.8
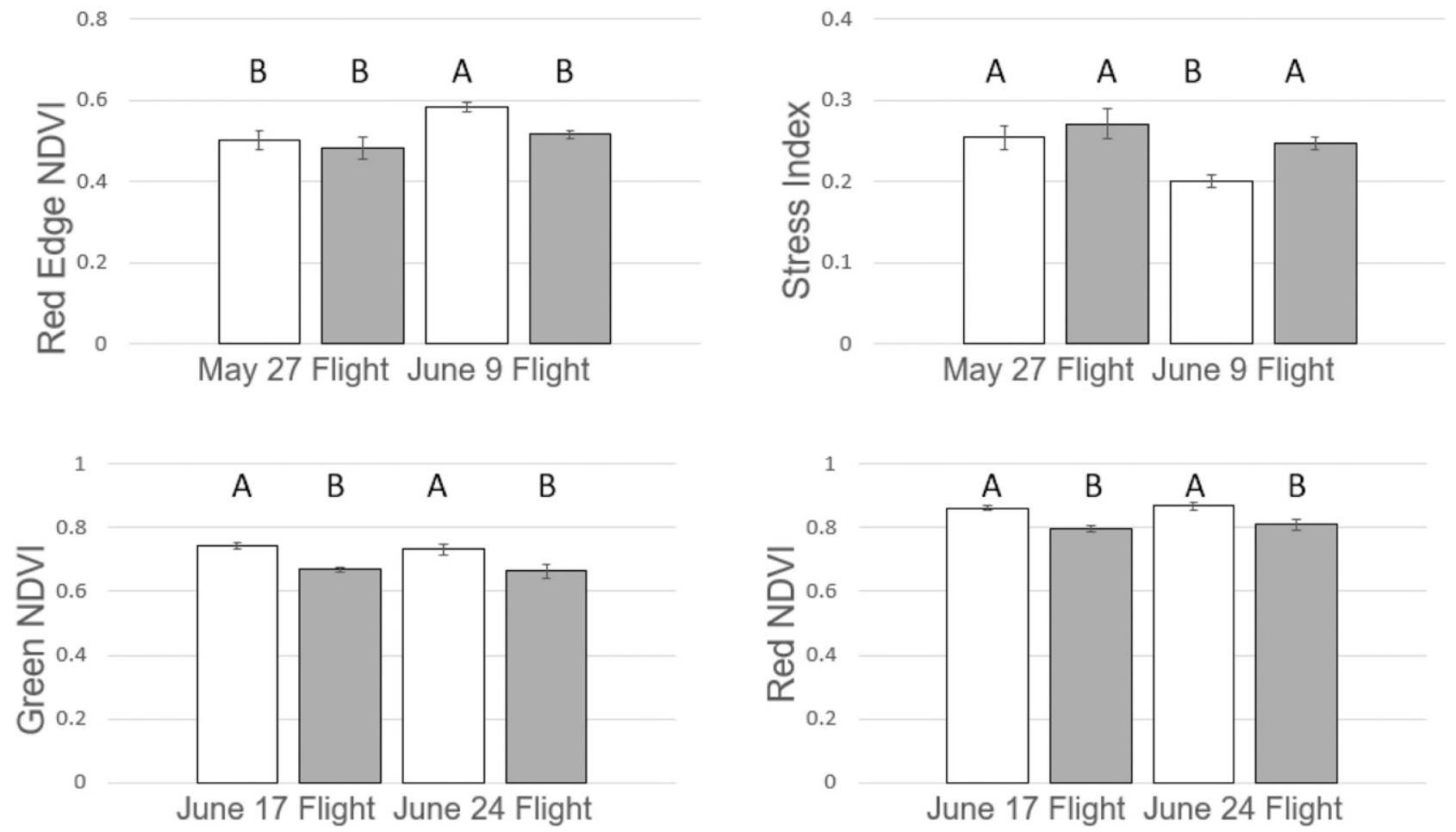

0.8

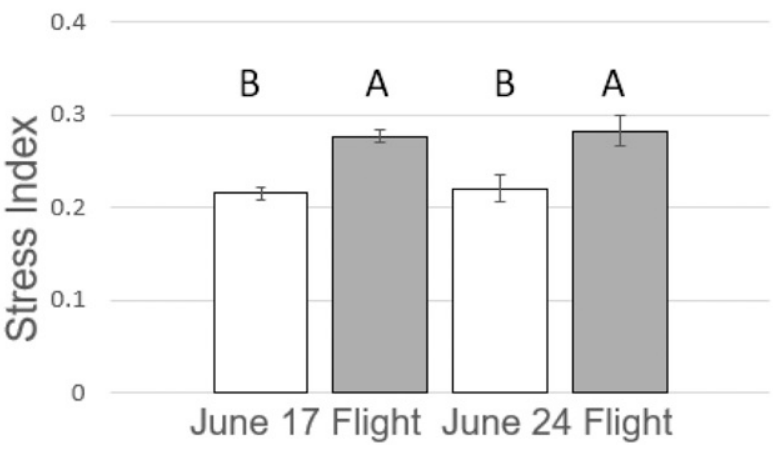

Fig. 4. Green normalized difference vegetation index (NDVI), red NDVI, red edge NDVI, and stress index values for conventional (white) and unmanned aerial vehicle-assisted (gray) scouting across four flight dates (May 27; June 9, 17 and 24, 2017) scouted by plant pathologists. Different letters above the bar indicate significant difference at $\alpha$ equal to $0.05(n=5)$. 
shifts were negative at 6.39, 15.32, and 9.76\% (Fig. 5), and for field 2 from June 17 to June 24, the shifts were negative at 13.19, 4.88, and $4.22 \%$ (Fig. 6).

Distribution of stress index for field 1 at scale ranges of 0.10 to 0.15 , and 0.15 to 0.20 showed a positive shift of $0.38 \%$ and a negative shift of $5.65 \%$, respectively (Fig. 5). For field 2, the same respective ranges showed a negative shift of $22.69 \%$ and a positive shift of $9.86 \%$ (Fig. 6)

\section{Discussion}

UAV-assisted scouting improved the field scouting procedure for watermelon disease detection owing to increased ability to identify disease foci and areas of concern more rapidly and consistently than conventional scouting practices. This is supported by greater disease severity values reported by scouts at UAV-assisted scouted areas compared with conventionally scouted areas. The multispectral images in the UAV-assisted scouting were valuable because they directed the scouts to potential disease foci. Similarly, maps based on the classification of multispectral sensor data have been developed to show severities and disease foci of wheat affected by viruses, downy mildew (Plasmopara viticola) affecting grapevine, and various pathogens affecting orchids (Mazzetto et al. 2010; NguyRobertson et al. 2016; Samseemoung et al. 2017). Gummy stem blight was the most common disease in watermelon fields in this study, and the effects of the pathogen were detected by calculating NDVIs and stress indices from multispectral sensor data collected with a UAV. Anthracnose, Fusarium wilt, Phytophthora fruit rot, Alternaria leaf spot, and cucurbit leaf crumple disease were confirmed by the scouts, but the incidence of these pathogens was too low to examine using multispectral imaging at the field scale. Identifying individual diseases would be useful, but knowing that there is a stress allows action to be taken to identify the possible threat. Multispectral imaging can be used to detect some diseases affecting some host plants (Herrmann et al. 2017; Zhang et al. 2018). However, not all diseases can be diagnosed using multispectral imagery. Hyperspectral imaging is the next level of technology for pathogen and disease detection (Mahlein et al. 2018).

Comparisons of NDVI values between locations of UAV-assisted scouted and conventional scouted sites were analyzed. The NDVI including green, red, and red edge captured green-up stages and chlorophyll content of the fields over time. Greater NDVIs indicated that the canopies were healthier and had greater chlorophyll content at the conventional scouted areas than at the UAV-assisted scouted locations, and this applies across three time points. Others have reported similar field dynamics of a positive relationship between NDVI and chlorophyll content, chlorophyll concentration, or overall health of plants and fields (Candiago et al. 2015; Jones et al. 2007).

Similarly to NDVI results, the stress index also captured the spatial and temporal dynamics of the watermelon fields. Greater stress indices were found at UAV-assisted scouting locations in comparison with conventional scouting locations. This indicates greater levels of stress at the UAV-assisted scouted areas than the conventional scouted locations and provides a relationship similar to the disease severity reported by the current field scouting procedures. As time progressed, stress index increased in the conventional scouted areas over time, whereas the stress index for the UAV-assisted scouting remained constant across flight dates. This clearly indicates that the individuals doing the scouting were not sampling the most seriously affected areas of the field using the conventional procedure. It is important in field scouting to capture the incidence of emerging pathogens and cause(s) for stress. Consistency in the indices for the UAV-assisted scouting locations across flight dates was detected and strongly suggests that multispectral imaging improves conventional scouting by providing consistency in locating disease. Consistency between individual accuracy and repeatability is a concern for plant disease assessments (Nutter et al. 1993). The use of multispectral images in the UAV-assisted scouting provides consistency in finding disease foci in the field and increases repeatability.

Earlier detection of disease foci is important to growers because it enables management decisions to be made before the disease spreads. Variable rate (application) technology (VRT) is becoming an important management strategy that growers can use to reduce expensive chemical inputs and practice sustainable environmental health habits (Zhang and Kovacs 2012). It involves heterogeneous rather than traditional homogenous treatments to a field (Aubert et al. 2012; Lan et al. 2017; Stafford 2000). This is critical for many pathogens, including gummy stem blight, that can cause extensive canopy defoliation and rapid spread if environmental conditions are warm and wet or humid, leading to severe yield losses (Keinath 2000). Preventative fungicide applications, sometimes multiple treatments, are required to manage gummy stem blight adequately on watermelon if the pathogen is present and environmental conditions are optimal (Keinath 1995, 2000). Our results indicate that VRT may be an option for managing gummy stem blight in commercial watermelon fields with implementation of multispectral imaging supported with UAV technology.

Our results show that multispectral imaging is advantageous in disease detection. Careful analysis of these data suggests that field evaluations should not solely rely on UAV-assisted multispectral imagery, because human inspection is needed to validate some diseases. In one of the fields both scouting types identified gummy stem blight as a moderate threat; however, only conventional scouting identified anthracnose as another potential threat. This highlights the necessity for human validation and proofing of disease in the identified field locations. This becomes especially important when treatment recommendations are different for different pathogen types. One of the main limitations to our study is that the interpretation of NDVIs should only be applied to watermelon planted with black plastic mulch. The color of mulch is known to influence the underlying microclimate conditions and absorption and reflection of radiation at the surface (Ham et al. 1993; Lamont 2005). The NDVI values in this study take into account these variables with the black mulch and, therefore, should not be applied at this point to other watermelon fields grown with different colors of mulch. Further studies are

Table 3. Summary of normalized difference vegetation index (NDVI) and stress index of conventional and unmanned aerial vehicle (UAV)-assisted scouting locations at field 1 collected on May 27 and June 9, 2017; and field 2 collected on June 17 and June 24, 2017

\begin{tabular}{|c|c|c|c|c|c|c|c|c|c|c|c|c|c|c|c|c|}
\hline \multirow[b]{2}{*}{ Date, type } & \multicolumn{4}{|c|}{ Green NDVI } & \multicolumn{4}{|c|}{ Red NDVI } & \multicolumn{4}{|c|}{ Red edge NDVI } & \multicolumn{4}{|c|}{ Stress index } \\
\hline & Low & High & Mean & SD & Low & High & Mean & SD & $\mathbf{w}$ & igh & Mean & SD & Low & Iigh & Mean & SD \\
\hline May 27, Conv. & 676 & 0.719 & 0.703 & 0.016 & .785 & 0841 & 0.81 & 02 & 57 & 0.534 & 0,5 & 0.024 & 233 & .273 & 0.254 & .014 \\
\hline $\mathrm{Ma}$ & 9 & & & & & & & & & & & & & 96 & & 17 \\
\hline nv. & 6 & 29 & 67 & 0 & & 4 & 0 & 0 & & & & & & 53 & 00 & 023 \\
\hline & 2 & 57 & 14 & 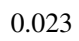 & & 1 & 0.826 & 0 & & 99 & & 2 & 9 & 12 & 47 & 0.021 \\
\hline onv. & 740 & 0.775 & 61 & 0.012 & & 0.8 & 0.880 & 0 & 60 & 0. & & 0.012 & & 0.217 & 0.202 & 0.009 \\
\hline June 17, UAV & 0.638 & 0.688 & 0.669 & 0.014 & 0.770 & 0.820 & 0.795 & 0.016 & 0.455 & 0.498 & 0.479 & 0.014 & 0.263 & 0.300 & 0.277 & 0.012 \\
\hline June 24, Conv. & 0.695 & 0.750 & 0.722 & 0.016 & 0.838 & 0.889 & 0.864 & 0.013 & 0.490 & 0.556 & 0.526 & 0.021 & 0.215 & 0.262 & 0.237 & 0.014 \\
\hline June 24, UAV & 0.597 & 0.717 & 0.666 & 0.046 & 0.741 & 0.858 & 0.811 & 0.042 & 0.410 & 0.533 & 0.472 & 0.042 & 0.235 & 0.337 & 0.282 & 0.037 \\
\hline
\end{tabular}

${ }^{\mathrm{a}}$ Conv. = conventional; UAV $=\mathrm{UAV}$-assisted; and $\mathrm{SD}=$ standard deviation of the mean. 
needed to evaluate if mulch types or type of cucurbits could affect reflectance.

This study demonstrates for the first time that UAV-assisted scouting improves the conventional technique because it enables earlier detection of pathogens that are of concern. In addition, this study also shows how trends in entire field dynamics in positive or negative shifts in NDVIs and stress index in individual fields can be monitored. Because the use of drone technology for agriculture remains relatively new, coupling conventional and drone-assisted scouting is the most effective strategy for pathogen detection and control. Advances in drone technology, including improvements in sensors, analysis software, and refined sampling methodology, and differentiation between pathogens and other stress types, have immediate application. These advances and development of disease-specific
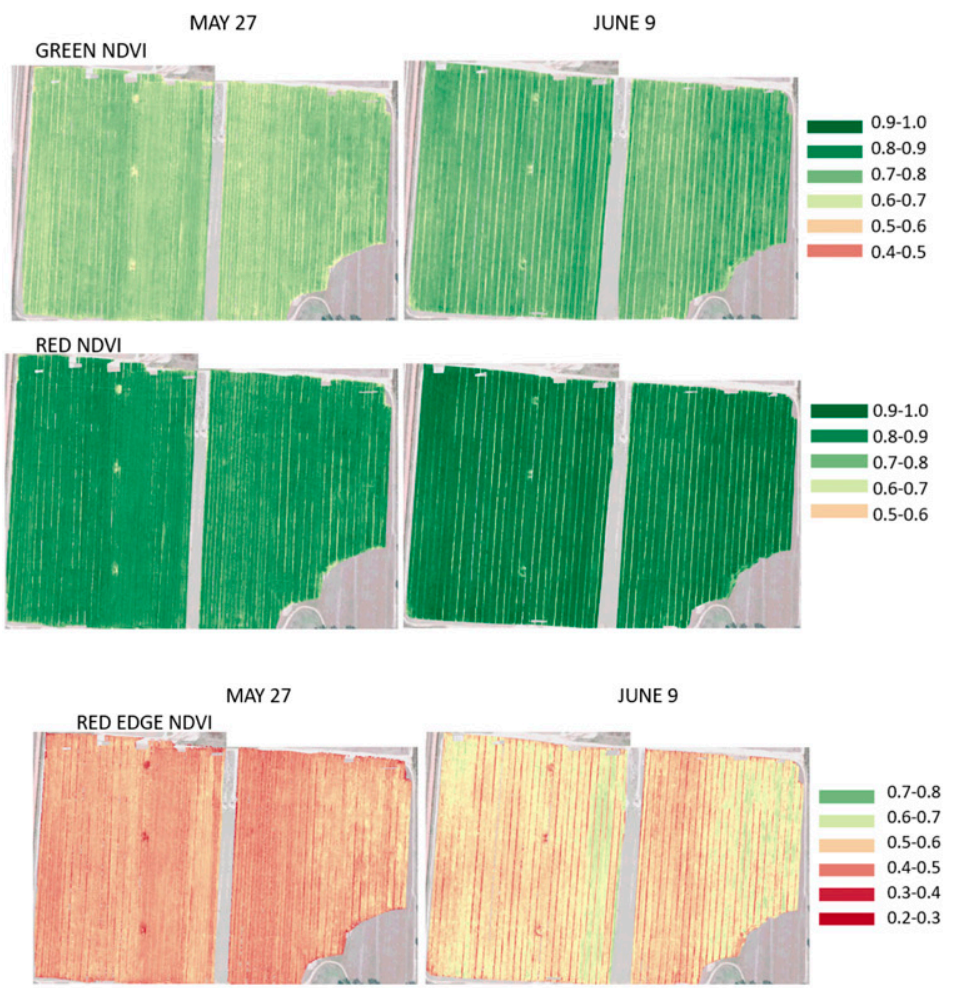

STRESS INDEX
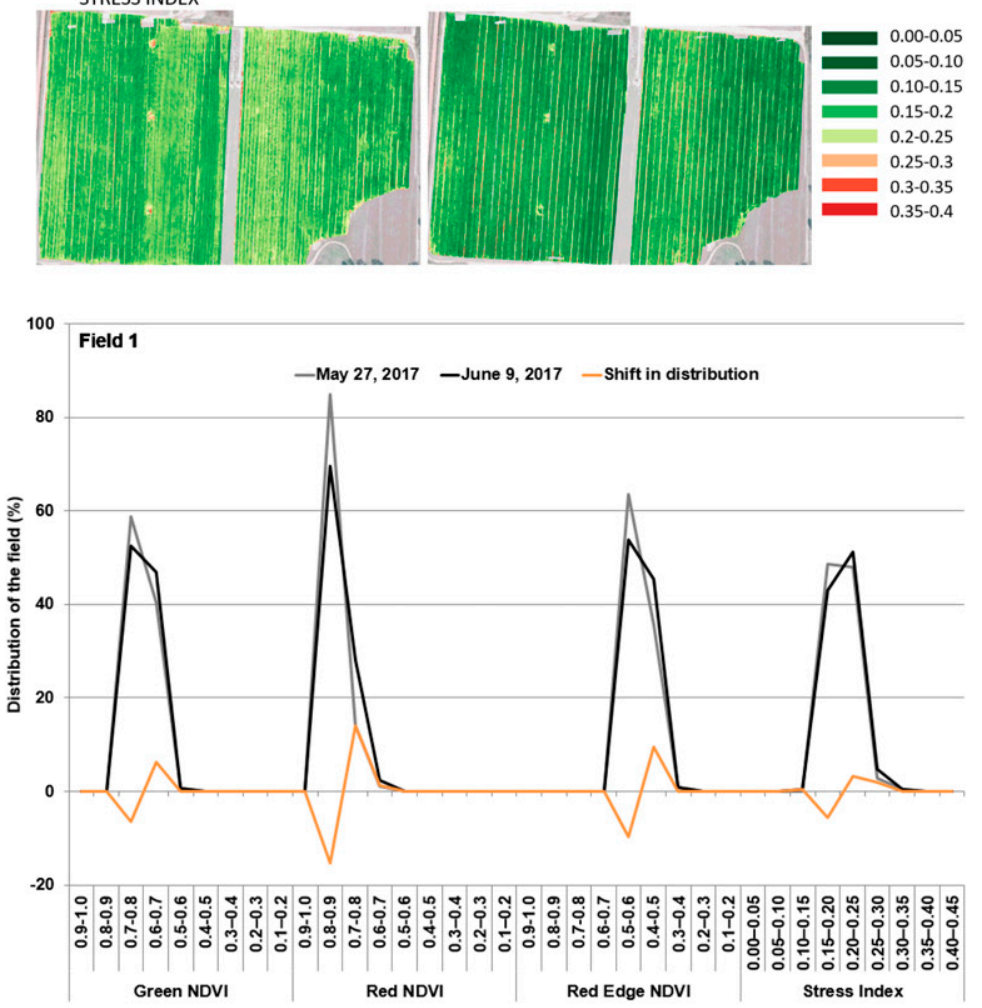

Fig. 5. Entire field multispectral sensor green, red, and red edge normalized difference vegetation index (NDVI) and stress index image and distribution map for field 1 (Florida) on May 27 and June 9, 2017. 
data analysis procedures will provide tremendous advantages in precision agriculture.

\section{Acknowledgments}

The authors acknowledge the support of Florida Watermelon Association (Laura Land), National Watermelon Association (Bob Morrissey), Bob Hochmuth, University of Florida, and the watermelon producers who supported this research.

JUNE 17

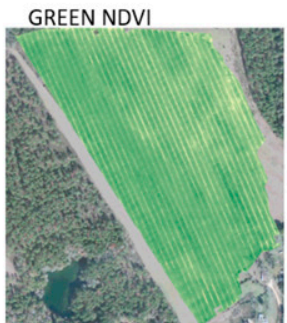

RED NDVI

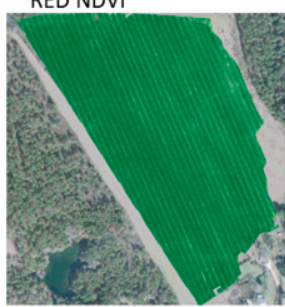

JUNE 17

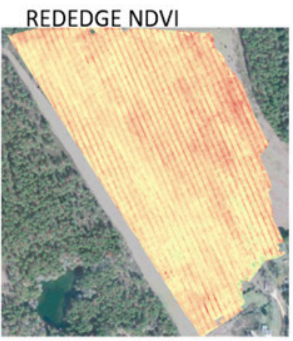

STRESS INDEX
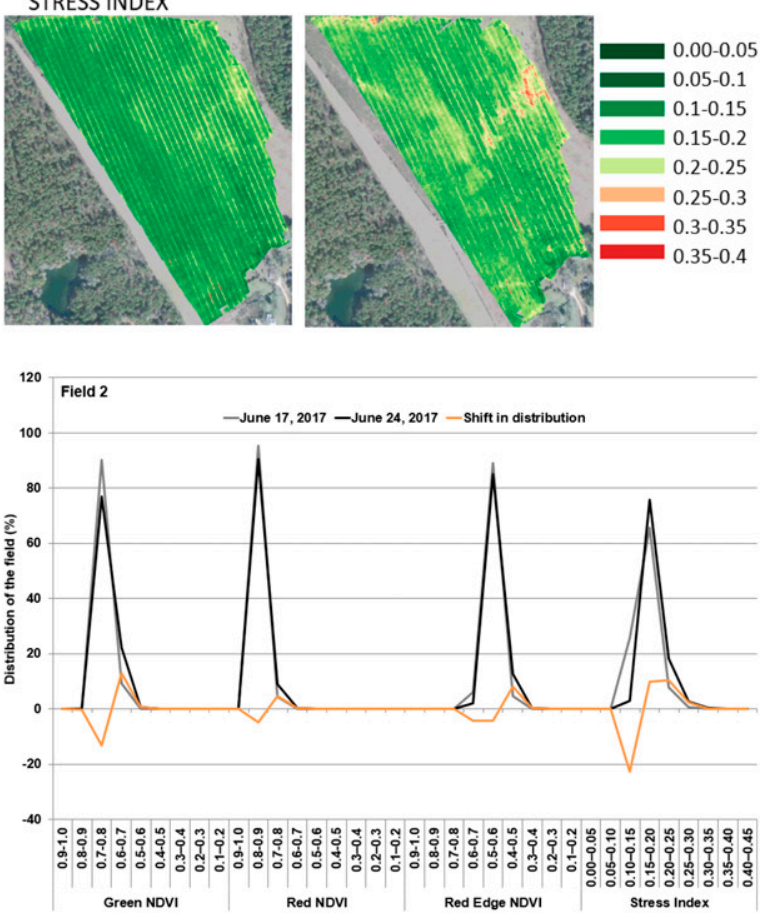

Fig. 6. Entire field multispectral sensor green, red, and red edge normalized difference vegetation index (NDVI) and stress index image and distribution map for field 2 (Georgia) on June 17 and June 24, 2017.

\section{Literature Cited}

Adkins, S., Webster, C. G., Kousik, C. S., Webb, S. E., Roberts, P. D., Stansly, P. A., and Turecheck, W. W. 2011. Ecology and management of whiteflytransmitted viruses of vegetable crops in Florida. Virus Res. 159:110-114.

Aubert, B. A., Schroeder, A., and Grimaudo, J. 2012. IT as enabler of sustainable farming: An empirical analysis of farmers' adoption decision of precision agriculture technology. Decis. Support Syst. 54:510-520.

Ballester, C., Hornbuckle, J., Brinkhoff, J., Smith, J., and Quayle, W. 2017. Assessment of in-season cotton nitrogen status and lint yield prediction from unmanned aerial system imagery. Remote Sens. 9:1149.

Barbosa, G. S., Lima, J. A. A., Nascimento, A. K. A., Silva, F. R., and Dias, R. C. S. 2017. Sources of resistance in accessions of Cucurbita spp. to virus species from the genus Potyvirus. Rev. Cienc. Agron. 48:725-731.

Basu, P. K., and Lin, C. S. 1977. A comparison of sampling methods for surveying alfalfa diseases. Can. J. Plant Sci. 57:1091-1097.

Berdugo, C. A., Zito, R., Paulus, S., and Mahlein, A. K. 2014. Fusion of sensor data for the detection and differentiation of plant diseases in cucumber. Plant Pathol. 63:1344-1356.

Bock, C. H., Pool, G. H., Parker, P. E., and Gottwald, T. R. 2010. Plant disease severity estimated visually, by digital photography and image analysis, and by hyperspectral imaging. Crit. Rev. Plant Sci. 29:59-107.

Candiago, S., Remondino, F., Giglio, M. D., Dubbini, M., and Gattelli, M. 2015 Evaluating multispectral images and vegetation indices for precision farming applications from UAV images. Remote Sens. 7:4026-4047.

Costes, E., Lauri, P. E., Simon, S., and Andrieu, B. 2013. Plant architecture, its diversity and manipulation in agronomic conditions, in relation with pest and pathogen attacks. Eur. J. Plant Pathol. 135:455-470.

Demmig-Adams, B., Cohu, C. M., Amlard, V., Zadelhoff, G., Veldink, G. A., Muller, O., and Adam, W. W. I. I. I. 2013. Emerging trade-offs-impact of phytoprotectants (PsbS, xanthophylls, and vitamin E) on oxylipins as regulators of development and defense. New Phytol. 197:720-729.

Freeman, J. H., Dittmar, P. J., and Vallard, G. E. 2016. Page 1 in: Commercial Vegetable Production in Florida. The Institute of Food and Agriculture Science, University of Florida, Gainesville, FL.

Gitelson, A. A., Kaufman, Y. J., and Merzlyak, M. N. 1996. Use of a green channe in remote sensing of global vegetation from EOS-MODIS. Remote Sens. Environ. 58:289-298.

Ham, J. M., Kluitenberg, G. J., and Lamont, W. J. 1993. Optical properties of plastic mulches affect the field temperature regime. J. Am. Soc. Hortic. Sci. 118:188-193.

Herrmann, I., Berenstein, M., Paz-Kagan, T., Sade, A., and Karnieli, A. 2017. Spectral assessment of two-spotted spider mite damage levels in the leaves of greenhouse-grown pepper and bean. Biosyst. Eng. 157:72-85.

Holmes, G. J., Ojiambo, P. S., Hausbeck, M. K., Quesada-Ocampo, L., and Keinath, A. P. 2015. Resurgence of cucurbit downy mildew in the United States: A watershed event for research and extension. Plant Dis. 99: 428-441.

Johnson, J. T., Lennox, J. A., Ujong, U. P., Odey, M. O., Fila, W. O., Edem, P. N., and Dasofunjo, K. 2013. Comparative vitamins content of pulp, seed and rind of fresh and dried watermelon (Citrullus lanatus). Int. J. Sci.Technol. 2:99-103.

Jones, C., Weckler, P. R., Maness, N. O., Jayasekara, R., Stone, M. L., and Chrz, P 2007. Remote sensing to estimate chlorophyll concentration in spinach using multi-spectral plant reflectance. Trans ASABE 50:2267-2273.

Kalischuk, M. L., Johnson, D., and Kawchuk, L. M. 2015. Priming with a doublestranded DNA virus alters Brassica rapa seed architecture and facilitates a defense response. Gene 557:130-137.

Keinath, A. P. 1995. Fungicide timing for optimum management of gummy stem blight epidemics on watermelon. Plant Dis. 79:354-358.

Keinath, A. P. 2000. Effect of protectant fungicide application schedules on gummy stem blight epidemics and marketable yield of watermelon. Plant Dis. 84:254-260

Keinath, A. P. 2014. Differential susceptibility of nine cucurbit species to the foliar blight and crown canker phases of gummy stem blight. Plant Dis. 98:247-254.

Keinath, A. P., and Duthie, J. A. 1998. Yield and quality reductions in watermelon due to anthracnose, gummy stem blight, and black rot. Recent Res. Dev. Plan Pathol. 2:77-90.

Kemble, J. M., Ivery, M. L. L., Jennings, K. M., and Walgenbach, J. F. 2016. Page 286 in: Southeastern U.S. Vegetable Crop Handbook. The Institute of Food and Agriculture Science, University of Florida, Gainesville, FL.

Kouakou, A. K., Bagui, O. K., Agneroh, T. A., Soro, A. P., and Zoueu, J. T. 2016. Cucumber mosaic virus detection by artificial neural network using multispectral and multimodal imagery. Optik (Stuttg.) 127:11250-11257.

Kousik, C. S., Ikerd, J. L., Wechter, P., Harrison, H., and Levi, A. 2012. Resistance to Phytophthora fruit rot of watermelon caused by Phytophthora capsici in U.S. plant introductions. HortScience 47:1682-1689.

Lamont, W. J., Jr. 2005. Plastics: Modifying the microclimate for the production of vegetable crops. HortTechnology 15:477-481.

Lan, Y. B., Chen, S. D., and Fritz, B. K. 2017. Current status and future trends of precision agricultural aviation technologies. Int. J. Agric. Biol. Eng. 10:1-17.

Lin, C. S., Poushinsky, G., and Mauer, M. 1979. An examination of five sampling methods under random and clustered disease distribution using simulation. Can. J. Plant Sci. 59:121-130. 
Link, J., Senner, D., and Claupein, W. 2013. Developing and evaluating an aerial sensor platform (ASP) to collect multispectral data for deriving management decisions in precision farming. Comput. Electron. Agric. 7:4026-4047.

Lo, S. C. C., and Nicholson, R. L. 1998. Reduction of light-induced anthocyanin accumulation in inoculated sorghum mesocotyls. Plant Physiol. 116:979-989.

Lowe, A., Harrison, N., and French, A. P. 2017. Hyperspectral image analysis techniques for the detection and classification of the early onset of plant disease and stress. Plant Methods 13:80.

Mahlein, A. K., Kuska, M. T., Behmann, J., Polder, G., and Walter, A. 2018. Hyperspectral sensor and imaging technologies in phytopathology: State of the art. Annu. Rev. Phytopathol. 56:535-558.

Marino, S., and Alvino, A. 2014. Proximal sensing and vegetation indices for sitespecific evaluation on an irrigated crop tomato. Eur. J. Remote Sens. 47:271-283.

Mazzetto, F., Calcante, A., Mena, A., and Vercesi, A. 2010. Integration of optical and analogue sensors for monitoring canopy health and vigour in precision viticulture. Precis. Agric. 11:636-649.

Moges, S. M., Rsun, W. R., Mullen, R. W., Freeman, K. W., Johnson, G. V., and Solie, J. B. 2005. Evaluation of green, red, and near infrared bands for predicting winter wheat biomass, nitrogen uptake, and final grain yield. J. Plant Nutr. 27:1431-1441.

Newberry, E. A., Ritchie, L., Babu, B., Sanchez, T., Beckham, K. A., Jones, J. B., Freeman, J., Dufault, N. S., and Paret, M. L. 2017. Epidemiology and management of bacterial leaf spot on watermelon caused by Pseudomonas syringae. Plant Dis. 101:1222-1229.

Nguy-Robertson, A. L., Zygielbaum, A. L., McMechan, A. J., Hein, G. L., Wegulos, N., Stilwell, A. R., and Smith, T. M. 2016. Developing the framework for a risk map for mite vectored viruses in wheat resulting from pre-harvest hail damage. Crop Prot. 89:21-31.

Nutter, F. W., Jr., Gleason, M. L., Jenco, J. H., and Christians, N. C. 1993. Assessing the accuracy, intra-rater repeatability, and inter-rater reliability of disease assessment systems. Phytopathology 83:806-812.
Polston, J. E., Hladky, L. L., Akad, F., and Wintermantel, W. M. 2008. First report of cucurbit yellow stunting disorder virus in cucurbits in Florida. Plant Dis. 92: 1251.

Rennberger, G., and Keinath, A. 2018. Susceptibility of fourteen new cucurbit species to gummy stem blight caused by Stagonosporopsis citrulli under field conditions. Plant Dis. 102:1365-1375.

Samseemoung, G., Soni, P., and Sirikul, C. 2017. Monitoring and precision spraying for orchid plantation with wireless WebCAMs. Agriculture 7:87.

Schuster, C., Förster, M., and Kleinschmit, B. 2012. Testing the red edge channel for improving land-use classifications based on high-resolution multi-spectral satellite data. Int. J. Remote Sens. 33:5583-5599.

Stafford, J. V. 2000. Implementing precision agriculture in the 21 st century. J. Agric. Eng. Res. 76:267-275.

Tivoli, B., Calonnec, A., Richard, B., Ney, B., and Andrivon, D. 2013. Current knowledge on plant/canopy architectural traits that reduce the expression and development of epidemics. Eur. J. Plant Pathol. 135:471-478.

Uebersax, J. S. 2006. User guide for the MH program (v. 1.1). http://john-uebersax. $\mathrm{com} / \mathrm{stat} / \mathrm{mh} . \mathrm{htm}$

Vergara-Diaz, O., Kefauver, S. C., Elazab, A., Nieto-Taladriz, M. T., and Araus, J. L. 2015. Grain yield losses in yellow-rusted durum wheat estimated using digital and conventional parameters under field conditions. Crop J. 3 200-210.

Walcott, R. R. 2005. Bacterial fruit blotch of cucurbits. The Plant Health Instructor doi: 10.1094/PHI-I-2005-1025-02

Zhang, C., and Kovacs, J. M. 2012. The application of small unmanned aerial systems for precision agriculture: A review. Precis. Agric. 13:693-712.

Zhang, D., Zhou, X., Zhang, J., Lan, Y., Xu, C., and Liang, D. 2018. Detection of rice sheath blight using an unmanned aerial system with high-resolution color and multispectral imaging. PLoS One 13:e0187470.

Zhou, X. G., and Everts, K. L. 2004. Suppression of Fusarium wilt of watermelon by soil amendment with hairy vetch. Plant Dis. 88:1357-1365. 